\title{
Low Dose Celecoxib Combined with Clozapine for Treatment of Schizophrenia: A Double Blind Randomized Clinical Trial
}

\author{
Roya Samadi ${ }^{1}$, Ali Akhoundpour Manteghi ${ }^{1, *}$, Mehri Baghban Haghighi ${ }^{2}$, Amin Azhari ${ }^{2}$, Shervin Assari ${ }^{3,4}$ \\ 1. Department of Psychiatry, Faculty of Medicine, Mashhad University of Medical Sciences, Mashhad, Iran \\ 2. Faculty of Medicine, Mashhad University of Medical Sciences, Mashhad, Iran \\ 3. Social Determinants of Health Research Center, University of Social Welfare and Rehabilitation Sciences, Tehran, Iran \\ 4. Department of Psychiatry, School of Public Health, University of Michigan, Ann Arbor, USA
}

*Corresponding Author: Ali Akhoundpour Manteghi, Ibn-e-Sina Hospital, Faculty of Medicine, Mashhad University of Medical Sciences, Mashhad, Iran

Email: manteghia@mums.ac.ir

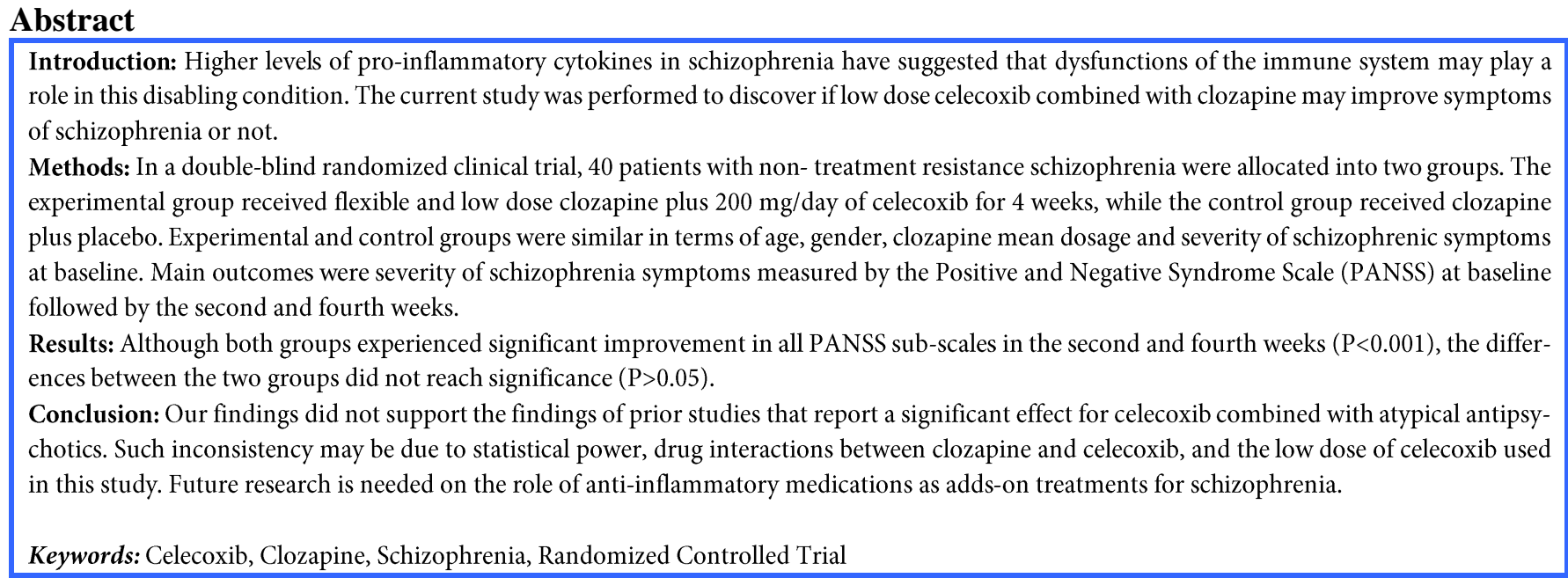

Article History: Received: 21 Aug 2014; Revised: 3 Nov 2014; Accepted: 26 Nov 2014

Cite this article as: Samadi R, Akhoundpour Manteghi A, Baghban Haghighi M, Azhari A, Assari S. Low dose celecoxib combined with clozapine for treatment of Schizophrenia: a double blind randomized clinical trial. Int J Travel Med Glob Health. 2015;3(1):11-7.

\section{Introduction}

Schizophrenia is a common catastrophic psychiatric disorder affecting almost all the aspects of personal, familial and social life. Since the available treatments are not sufficient enough [1], the recent approach is on its basic etiology and immune dysfunctions are most accused. A great deal of research has suggested that inflammatory cytokines and Microglial activation play an important role in the development of schizophrenia, as well as many other psychiatric disorders [2, 3]. Microglia, which are the main CNS immune cells, produce free radicals and proinflammatory cytokines even in minor pathological changes of CNS [3].

Sirota and colleagues indicated an enhanced level of IL-1, TNF- $\alpha$ and IL-3 in patients with schizophrenia $[4,5]$. Licino et al showed that cerebrospinal fluid (CSF) level of IL-2 is higher than normal in patients with schizophrenia not receiving psychotropic agents [6]. Then, McAllister et al claimed that the enhancement rate of IL-2 in these patients is related to the frequency of recurrence and prognosis [7]. Muller et al showed that soluble receptor of IL-6 increases in CSF and serum of patients [8]. Also, Kammen et al declared that IL-10 is involved in their behavioral disorders [9]. Further research showed that type 1 and type 2 immune systems are imbalanced in these patients. Exactly, type- 2 system is activated, while type- 1 is blunted [10].

Enhancement of pro-inflammatory cytokines in the central nervous system (CNS) results in the cognitive disturbances, perhaps mediated by the cyclo-oxygenase-2 (COX-2) enzyme [11], interacting with acetylcholine, 5hydroxytryptamine, glutamate and prostaglandin E2 [12]. COX-2 enzyme may be involved with schizophrenia through some probable ways. It is found in neurons [13], and can be activated by some cytokines (such as IL-2, IL-6 and IL-10) which have an important role in the development of schizophrenia [14-17]. On the other hand, it is probable that the interference of COX-2 with the functions of glutamate receptors in hippocampus and amygdale is responsible for the development of this disease [18].

Based on the hypothesis of the dysfunctions of the immune system, immune-modulatory medication may reduce the symptoms of schizophrenia. Recent clinical trials of pharmacotherapy in schizophrenia have shown that coadministration of antipsychotic and anti-inflammatory 
drugs have superior beneficial effects comparing with outcomes of using antipsychotic drugs alone [19].

Celecoxib is a selective inhibitor of COX-2 enzyme, approved for the treatment of osteoarthritis [20]. It is permeable in CNS and has been beneficial in some neurologic disorders, such as Alzheimer's disease [18, 21]. Rebalancing the type- 1 and type- 2 immune responses, it probably decreases the production of pro-inflammatory cytokines [10, 22]. Celecoxib has been effective on animal models of schizophrenia. In a study, the injection of the epidermal growth factor (a molecule that is thought to be responsible for the development of schizophrenic symptoms) into striatum of rats, increased COX-2 expression and induced behavioral impairments. Then, the administration of oral celecoxib (10 $\mathrm{mg} / \mathrm{kg}$ ) normalized the metabolism of dopamine and, again, ameliorated those behavioral impairments [23]. In the recent decade, some controlled clinical trials were conducted concerning the benefits of COX-2 inhibitors in schizophrenia and suggested that celecoxib, as an add-on to atypical antipsychotics, particularly risperidone, is capable to reduce the symptoms of schizophrenia [14, 22, 23]. However, there were some inconsistent results, as well [24, 25].

In order to achieve the best clinical efficacy and minimal side effects of most antipsychotics, there is a narrow therapeutic window of 65-78\% D [2] receptor blockade, but clozapine do not have that therapeutic window and makes sub-threshold levels of D [2] blockade [26]. However, several studies indicate that patients with schizophrenia who are resistant to other antipsychotics may be treated successfully by clozapine [26-29]. Some studies demonstrate that clozapine has immune-modulatory activities [28]. Risperidone, clozapine and COX-2 enzyme affect serotonergic and cholinergic receptors in different ways $[12,27,29,30]$. The Clozapine effect on serotonin (5-HT) receptors has a major role in the efficacy and tolerability of clozapine and it is important in amelioration of psychosis and cognitive impairment [31]. A proportion of patients with schizophrenia require clozapine therapy and this drug is different from the other atypical antipsychotics in some aspects. Furthermore, the role of anti-inflammatory drugs such as celecoxib have been distinguished in several studies.

The present study was performed to assess the effect of low dose celecoxib add-on to clozapine for the treatment of patients with schizophrenia.

\section{Methods}

\subsection{Design and Setting}

This double-blind randomized clinical trial (phase 3) -approved by the ethics committee of Mashhad University of Medical Science, enrolled 40 patients with schizophrenia admitted in Ibne-e-Sina psychiatric hospital of Mashhad city, northeastern Iran, were selected in 2006.

\subsection{Participants}

The inclusion criteria was the diagnosis of schizophrenia based on the DSM-IV criteria by two psychiatrists and treatment resistance schizophrenia (based on research trials, 1-3 trials that used adequate doses of antipsychotic drugs, each lasting for more than 4-6weeks, have failed to reduce positive symptoms sufficiently) [32]. The exclusion criteria included the use of any oral antipsychotic except clozapine since the last week, use of long acting antipsychotics since the last month, use of other psychotropic medications such as antidepressants and mood stabilizers (Biperidine/PRN for extrapyramidal complications was exceptional), severe drug side effects and the release of the patients from the hospital before the end of the experiment.

\subsection{Process}

After providing the necessary explanation about the project for the patients' protectors by psychiatrists, an informed consent was signed by the protector of each patient. Then, Demographic data was recorded.

Participants were randomly divided into 2 groups. The experimental group received flexible dosages of clozapine (based on clinical response) Leponex from Novartis company plus 200 milligrams of celecoxib from Abidi company per day in 2 divided doses for 4 weeks, while the control group received flexible dosages of clozapine (Leponex) plus placebo. We preferred a period of 4 weeks, because the majority of patients got a considerable improvement in 4 weeks and persisted to be released from the hospital. During these 4 weeks, 5 patients due to their family's decision for early discharge from the hospital, were excluded.

Low dosages of celecoxib (200 mg/day) in comparison with $400 \mathrm{mg} /$ day in the similar study [14] was cautiously preferred, because there was not any research prescribing the combination of clozapine and celecoxib in human beings before this study and adverse drug interactions were not completely predictable. Also, evidence has suggested that COX-2 inhibitors enhance the probability of seizure [33], which is a side effect of clozapine too. Moreover, a study has shown a side effect of auditory hallucination for celecoxib [34]. Therefore, in the present study, we agreed on $200 \mathrm{mg} /$ day of celecoxib.

\subsection{Outcome}

Main outcome was severity of schizophrenic symptoms evaluated by the positive and negative syndrome scale (PANSS) test [35]. The PANSS consists of 30 main questions (7 questions for positive symptoms, 7 questions for negative symptoms and 16 questions for general psychopathology). The potential score of each was between 1 (absence of symptom) to 7 (excessive symptom), thus the total PANSS score ranges from 30 to 210 . Higher PANSS reflects more severe symptoms. The PANSS test has been shown to be correlated with criterion measures, with an inter-rater reliability about 0.80 [36]. The Cronbach's alpha of Iranian version has been 0.73 to 0.83 [37].

The evaluation was performed at zero, second and fourth weeks. All questionnaires were fulfilled by a certain person, to avoid any bias. As the study was double-blind, neither the patient, nor the evaluator, were aware that the patient is receiving true medicine or placebo. Finally, data were analyzed 
by using the SPSS software version 13 , using chi-square and Fisher's exact tests for the assessment of homogeneity of 2 groups, paired $t$ test for evaluation of improvement in each group during the experiment and independent $t$ test for the comparison of the improvement rate of 2 groups.

\subsection{Statistical Power}

It should be noted that when calculating the sample size in the present study, a similar study on the combination of clozapine and celecoxib was not found for calculating the sample size according to its results, thus at first pilot study on 20 patients (10 in each group, participants who were randomly selected from eligible patients) was performed. Based on the results, the sample size in each group calculated 16 , considering alpha $=0.05$ and beta $=0.2$. , but according to $15 \%$ drop out in the pilot study, to reach the minimum in each group, 40 eligible patients were randomly assigned to two groups of 20. Finally, a group of 17 control patient and the other 18 patients were studied.

\section{Results}

In this study, 40 patients with schizophrenia participated and were randomly divided into 2 equal groups. The experimental group received clozapine and celecoxib, while the control group received clozapine and placebo. No adverse drug side effects was seen in patients during the experiment. As 5 non-cooperative patients left the study, it continued with 35 patients (17 and 18 patients in experimental and control groups, respectively).

The experimental group consisted of 15 men and 2 women, while the control group included 15 men and 3 women. Fisher's exact test showed that there was not a significant gender difference between 2 groups $(\mathrm{P}=0.582)$. Mean age in experimental and control groups was $29.4 \pm 14.3$ and $27.8 \pm 14.2$ years, respectively and independent $t$ test showed that they were not significantly different $(\mathrm{P}=0.480)$. Mean dosage of clozapine in experimental and control groups was $88.29 \pm 15.86$ and $87.28 \pm 14.97 \mathrm{mg} /$ day, respectively and independent $\mathrm{t}$-test showed that it was not significantly different $(\mathrm{t}=0.949, \mathrm{P}=0.350)$. Also, chi-square test showed that frequency of hospitalization was similar in 2 groups (X2 $=1.7$, $\mathrm{df}=3, \mathrm{P}=0.633$ ). The demographic information of the study groups have been indicated in table 1 .

Table1. The demographic data of the study participants based on group

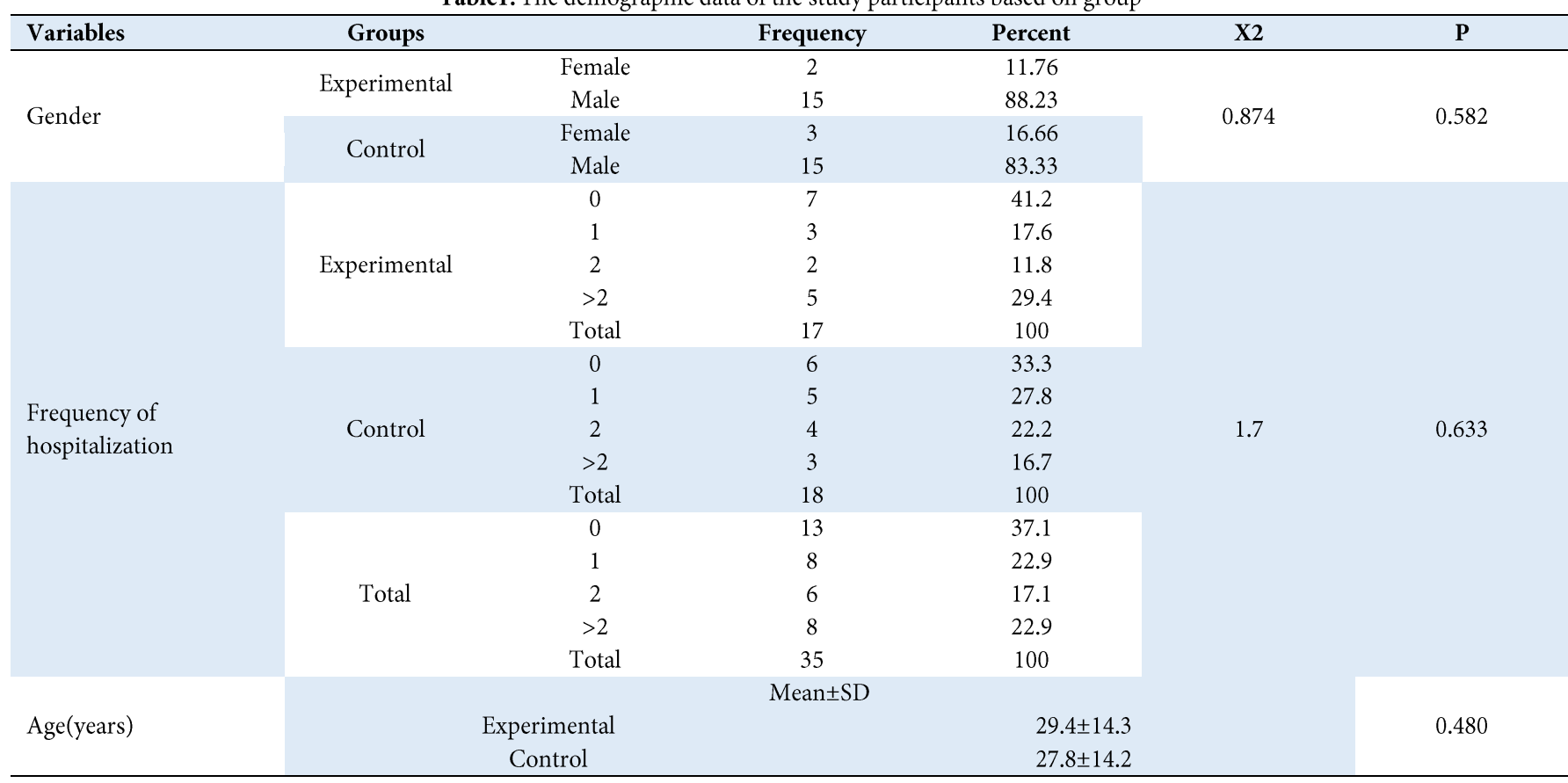

Table 2. Paired t test for comparison of positive and negative syndrome scale (PANSS) sub-scales between 0 , 2nd and 4 th weeks in each of experimental and control groups (Both groups had a significant improvement of all PANSS sub-scales in 2nd and 4th weeks)

\begin{tabular}{|c|c|c|c|c|c|c|c|c|c|c|c|}
\hline \multirow{2}{*}{$\begin{array}{l}\text { Positive and Negative } \\
\text { Syndrome Scale } \\
\text { (PANSS) Sub-scales }\end{array}$} & \multirow[t]{2}{*}{ Group } & \multicolumn{2}{|c|}{0 week } & \multicolumn{2}{|c|}{ 2nd week } & \multicolumn{2}{|c|}{ 4th week } & \multicolumn{2}{|c|}{$\begin{array}{c}\text { Comparison between } \\
0 \text { and } 2 \text { nd weeks }\end{array}$} & \multicolumn{2}{|c|}{$\begin{array}{l}\text { Comparison between } \\
\text { 2nd and 4th weeks }\end{array}$} \\
\hline & & Mean & SD & Mean & SD & Mean & SD & $\mathbf{t}$ & $\mathbf{P}$ & $\mathbf{t}$ & $\mathbf{P}$ \\
\hline \multirow{2}{*}{ Positive symptoms } & Experimental & 29.94 & 4.88 & 26.35 & 4.04 & 23.88 & 3.44 & 8.450 & $<0.001$ & 8.154 & $<0.001$ \\
\hline & control & 29.83 & 4.88 & 26.72 & 3.51 & 24.66 & 3.62 & 8.390 & $<0.001$ & 8.132 & $<0.001$ \\
\hline \multirow{2}{*}{ Negative symptoms } & Experimental & 30.24 & 4.53 & 26.52 & 4.19 & 23.05 & 3.76 & 8.374 & $<0.001$ & 8.265 & $<0.001$ \\
\hline & control & 30.11 & 3.85 & 26.77 & 3.7 & 23.94 & 3.66 & 8.354 & $<0.001$ & 8.305 & $<0.001$ \\
\hline \multirow{2}{*}{$\begin{array}{l}\text { General psycho- } \\
\text { pathology }\end{array}$} & Experimental & 47.94 & 8.12 & 43.82 & 7.78 & 41.58 & 7.41 & 7.879 & $<0.001$ & 7.359 & $<0.001$ \\
\hline & control & 47.82 & 85.4 & 44 & 8.02 & 42.5 & 7.74 & 7.536 & $<0.001$ & 7.383 & $<0.001$ \\
\hline \multirow{2}{*}{ Total score } & Experimental & 108.12 & 16.30 & 96.7 & 14.85 & 88.52 & 13.43 & 8.235 & $<0.001$ & 8.149 & $<0.001$ \\
\hline & control & 107.83 & 15.56 & 97.5 & 13.56 & 90.66 & 12.88 & 8.192 & $<0.001$ & 8.180 & $<0.001$ \\
\hline
\end{tabular}


Table 3. Independent $t$ test for comparison of positive and negative syndrome scale scores between experimental and control groups: Difference between two groups isn't significant

\begin{tabular}{|c|c|c|c|c|c|c|c|}
\hline $\begin{array}{l}\text { Positive and Negative Syndrome Scale (PANSS) } \\
\text { Subscales }\end{array}$ & Time & Group & Mean & SD & df & $\mathbf{t}$ & $\mathbf{P}$ \\
\hline \multirow{3}{*}{ Positive symptoms } & 0 week & $\begin{array}{l}\text { Experimental } \\
\text { control }\end{array}$ & $\begin{array}{l}29.94 \\
29.83\end{array}$ & $\begin{array}{l}4.88 \\
4.88\end{array}$ & 33 & 0.1 & 0.984 \\
\hline & 2nd week & $\begin{array}{l}\text { Experimental } \\
\text { control }\end{array}$ & $\begin{array}{l}26.35 \\
26.72\end{array}$ & $\begin{array}{l}4.05 \\
3.51\end{array}$ & 33 & 0.3 & 0.774 \\
\hline & 4th week & $\begin{array}{l}\text { Experimental } \\
\text { control }\end{array}$ & $\begin{array}{l}23.88 \\
24.67\end{array}$ & $\begin{array}{l}3.44 \\
3.63\end{array}$ & 33 & 0.7 & 0.517 \\
\hline \multirow{3}{*}{ Negative symptoms } & 0 week & $\begin{array}{l}\text { Experimental } \\
\text { control }\end{array}$ & $\begin{array}{l}30.24 \\
30.11\end{array}$ & $\begin{array}{l}4.53 \\
3.85\end{array}$ & 33 & 0.1 & 0.931 \\
\hline & 2nd week & $\begin{array}{l}\text { Experimental } \\
\text { control }\end{array}$ & $\begin{array}{l}26.53 \\
26.78\end{array}$ & $\begin{array}{l}4.2 \\
3.7\end{array}$ & 33 & 0.2 & 0.854 \\
\hline & 4 th week & $\begin{array}{l}\text { Experimental } \\
\text { control }\end{array}$ & $\begin{array}{l}23.06 \\
23.94\end{array}$ & $\begin{array}{l}3.77 \\
3.67\end{array}$ & 33 & 0.7 & 0.486 \\
\hline \multirow{3}{*}{ General psychopathology } & 0 week & $\begin{array}{l}\text { Experimental } \\
\text { control }\end{array}$ & $\begin{array}{l}47.94 \\
47.82\end{array}$ & $\begin{array}{l}8.12 \\
85.4\end{array}$ & 33 & 0.1 & 0.985 \\
\hline & 2nd week & $\begin{array}{l}\text { Experimental } \\
\text { control }\end{array}$ & $\begin{array}{l}43.82 \\
44.00\end{array}$ & $\begin{array}{l}7.79 \\
8.02\end{array}$ & 33 & 0.1 & 0.948 \\
\hline & 4 th week & $\begin{array}{l}\text { Experimental } \\
\text { control }\end{array}$ & $\begin{array}{l}41.59 \\
42.06\end{array}$ & $\begin{array}{l}7.42 \\
7.75\end{array}$ & 33 & 0.2 & 0.857 \\
\hline & 0 week & $\begin{array}{l}\text { Experimental } \\
\text { control }\end{array}$ & $\begin{array}{l}108.12 \\
107.83\end{array}$ & $\begin{array}{l}16.30 \\
15.56\end{array}$ & 33 & 0.1 & 0.958 \\
\hline Total score & 2nd week & $\begin{array}{l}\text { Experimental } \\
\text { control }\end{array}$ & $\begin{array}{l}96.71 \\
97.50\end{array}$ & $\begin{array}{l}14.86 \\
13.57\end{array}$ & 33 & 0.2 & 0.870 \\
\hline & 4 th week & $\begin{array}{c}\text { Experimental } \\
\text { control }\end{array}$ & $\begin{array}{l}88.53 \\
90.67 \\
\end{array}$ & $\begin{array}{l}13.43 \\
12.88 \\
\end{array}$ & 33 & 0.5 & 0.634 \\
\hline
\end{tabular}

Experimental and control groups had similar PANSS scores (regarding positive symptoms, negative symptoms, general psychopathology and total score) at the baseline $(\mathrm{P}>0.05)$. Paired t test showed that both experimental $(\mathrm{P}<0.001)$ and control $(\mathrm{P}<0.001)$ groups experienced a significant improvement of all sub-scales of PANSS in both second and fourth weeks. Improvement of PANSS scores during the experiment in experimental group was a little better than the control group, however, independent $t$ test showed that it was not significant $(\mathrm{P}>0.05)$ (tables $2 \& 3)$.

\section{Discussion}

Although both groups experienced significant improvement in all PANSS domains in second and fourth weeks $(\mathrm{P}<0.001)$, the difference between the two groups were not significant ( $P>0.05$ ). This finding did not support results of prior studies that report a significant effect for celecoxib as an add-on to atypical antipsychotics.

The considerable improvement is observed in the second week of treatment and remains significant even until the fourth week. However, $200 \mathrm{mg} /$ day of celecoxib is not prior than placebo to provide a significant improvement.

Studies suggest that inflammatory system activities can deteriorate some functions in schizophrenia such as cognitive affective, emotional and social functions. It means inflammatory system has a role in the development of schizophrenia especially in negative and cognitive symptoms [19].

For the first time in 2002, Muller and colleagues showed that 5 weeks of treatment with risperidone (2-6 mg/day) plus celecoxib (400 mg/day) improves positive, negative and total symptoms of schizophrenia better than risperidone alone [14]. This provoked a number of studies about the role of
COX-2 inhibitors in the treatment of schizophrenia. The priority of 8 weeks of treatment with risperidone $(6 \mathrm{mg} /$ day $)$ plus celecoxib (400 mg/day) compared to risperidone alone for the improvement of positive symptoms, general psychopathology and PANSS total score was emphasized by Akhondzadeh et al. Though, the rate of extrapyramidal side effects was not significantly affected [22]. A study on patients with the first manifestation of schizophrenia demonstrated that $400 \mathrm{mg} /$ day of celecoxib plus $200-1000 \mathrm{mg} /$ day of amisulpride, affects the negative symptoms, as well as the general psychopathology and PANSS total score [27]. Also, in another study it was detected that celecoxib ameliorates the cognition of patients with schizophrenia [38].

These findings support the hypothesis that an immunological dysfunction exists in the pathogenesis of schizophrenia and COX-2 enzyme is involved here. However, in a study celecoxib was not capable of altering the cytokine levels in patients with schizophrenia receiving stable doses of olanzapine or risperidone [39].

Although most of the studies concerning the benefits of COX-2 inhibitors were promising, Rapaport et al did not find any advantage in using $400 \mathrm{mg} /$ day of celecoxib for 8 weeks compared to placebo, in treatment of continuously ill schizophrenic outpatients receiving a stable dose of an atypical antipsychotic [24]. In a cohort, Stolk et al showed that exposure to COX-2 inhibitors in patients with schizophrenia using antipsychotics may not decrease the risk of deterioration [25].

A number of probable reasons are suggested for these inconsistent results concerning the effect of celecoxib in schizophrenia. Muller prescribed $400 \mathrm{mg}$ /day of Celebrex [14], while in the present study our patients received low dosages 
of celecoxib (200 mg/day) of an Iranian drug corporation. This difference of dosage and efficacy could affect the therapeutic results with a high probability.

Evidence shows that clozapine can be effective on patients with schizophrenia who are resistant to other antipsychotics [27]. This high efficacy of clozapine may have reached our patients to maximum of therapeutic outcomes and prevented the probable therapeutic effects of celecoxib to appear.

Drug interactions may also impress the results in several ways. For instance, if celecoxib has the ability to induce the metabolism of clozapine, as the metabolites of clozapine have very little antipsychotic affects compared to metabolites of risperidone [27], it will reduce the efficiency of combination of clozapine and celecoxib, compared to risperidone and celecoxib. On the other hand, the COX-2 enzyme interacts with both serotonergic and cholinergic receptors [12]. Clozapine and risperidone, both affect these receptors, but in different ways [27, 30]. So, it would not be amazing if clozapine and risperidone had different interactions with COX-2 inhibitors, resulting in inconsistent results.

It is notable that most studies have focused on other atypical antipsychotics, except closapine. A recent study indicates anti-inflammatory effects of some atypical antipsychotics via inhibition of activated microglia. Maybe clozapine works in different ways [40]. Extended studies are needed to clarify this.

Nutrition and habitual behaviors may also interact. For instance, smoking cigarette decreases the effect of several antipsychotic, through an unknown way [41]. Also, excessive consumption of vitamin $\mathrm{C}$ reduces the effect of fluphenazine [42]. Laboratory research suggests that xanthine of tea and coffee interacts with the effects of neuroleptics [43], however a study on human beings did not confirm that effect [44]. Finally, as it was said, increases of the CSF level of IL-2 results in the appearance of the treatment resistant cases of schizophrenia [7]. It is said that colzapine is effective on resistant cases [27]. So, clozapine may have some immunologic effects and functions through reducing the CSF level of IL-2. These probable immunologic effects must be regarded too.

In some cases, patients who had improvement, persisted to release before completing the experiment and this made some disturbances. Also, it was appropriate to evaluate plasma levels of consumed drugs and their metabolites to declare if there is an interaction between them or not, but it did not become available at the moment.

Although this study did not confirm that $200 \mathrm{mg} /$ day of celecoxib, as an add-on to clozapine, has a significant additional effect on schizophrenia symptoms comparing with clozapine alone, the selection of a low dosage and some probable interfering factors, suggest that more precise, extensive and controlled studies are required in this field. There are only few studies about the relationship between the unique adverse and therapeutic effects of clozapine. Approximately half of the patients develop fever and flu like syndrome during the first month of clozapine administration. Furthermore, the risk of side-effects increases within the same time. Both of these events, may be related to increasing cytokines and immunological system activities [28], so co administration of clozapine and low doses of celecoxib may prevent some adverse effects of clozapine without decreasing the therapeutic effects of clozapine. Further investigations in this field are suggested to clarify this.

As peripheral and central inflammatory responses of schizophrenic patients are activated and have a role in negative and cognitive symptoms of schizophrenia [19], augmentation of anti-inflammatory drugs such as celecoxib may be useful. Additional benefits can be due to reducing some comorbid somatic diseases and mortality rate of cancer in these patients [45]. However, further research is deserved.

\section{Conclusion}

Regarding the safety of the combination of celecoxib and clozapine that was observed in patients with schizophrenia, it will be appropriate for the next studies to use high dosages of celecoxib, which may be more efficient. Following patients for more weeks, may appear some long term therapeutic effects of clozapine and celecoxib co-administration. In less acute cases, it is better to evaluate the antipsychotic effects of celecoxib, as a mono-therapy, to avoid drug interactions. Otherwise it is suitable to measure the plasma levels of drugs in order to interpret more precisely. Environmental factors, such as nutrition and smoking should be controlled too. It will be appropriate to assess the plasma and CSF levels of inflammatory cytokines simultaneously. Studying genes responsible for the appearance of different efficiency of antipsychotics in different people would be beneficial too. As some COX-2 inhibitors such as refecoxib have been shown promising in other psychiatric disorders, such as depression, they require appropriate clinical trials to be done [12]. Conducting clinical trials concerning the benefits of other neuroprotective agents, such as memantine are useful as well [46]. The next studies will be hopeful to provide more efficient treatments for schizophrenia, in order to approach its definite cure.

\section{Acknowledgements}

We should thank Vice chancellor of Mashhad University of Medical Sciences, Parisa Samadi and the staff of inpatient wards of Ibn-e-Sina Hospital.

\section{Authors' Contributions}

Ali Akhoundpour Manteghi: Data collection, study design, contribution to the manuscript. Roya Samadi: Literature search, concept and design of the study, editing and review of the manuscript. Mehri Baghban Haghighi: Statistical analysis, literature search of manuscript, manuscript preparation. Amin Azhari: Data collection, study design, literature 
search of manuscript. Shervin Assari: Study design, and contribution to the manuscript draft and revision.

\section{Funding/Support}

This research received a grant from the Vice-chancellor of Research of Mashhad University of Medical Sciences. Funding source did not interfere with data collection, analysis, or interpretation of data. This research was performed as a thesis after approval by the research and ethics committees of Mashhad University of Medical Sciences.

\section{Financial Disclosure}

No conflict of interest is declared by any of the authors.

\section{References}

1. Sadock BJ, Sadock VA. Kaplan \& Sadock's comprehensive textbook of psychiatry. 9th ed. Philadelphia: Lippincott Williams \& Wilkins; 2009, pp. 1432-1629.

2. Müller N, Ackenheil M. Psychoneuroimmunology and the cytokine action in the CNS: implications for psychiatric disorders. Prog Neuropsychopharmacol Biol Psychiatry. 1998;22(1):1-33.

3. Monji A. The neuroinflammation hypothesis of psychiatric disorders Seishin Shinkeigaku Zasshi. 2012;114(2):124-33. [Article in Japanese]

4. Sirota P, Schild K, Elizur A, Djaldetti M, Fishman P. Increased interleukin-1 and interleukin-3 like activity in schizophrenic patients. Prog Neuropsychopharmacol Biol Psychiatry. 1995;19(1):75-83.

5. Chen SL, Lee SY, Chang YH, Chen SH, Chu CH, Tzeng NS, et al. Inflammation in patients with schizophrenia: the therapeutic benefits of risperidone plus add-on dextromethorphan. J Neuroimmune Pharmacol. 2012;7(3):656-64.

6. Licino J, Seibyl JP, Altemus M, Charney DS, Krystal JH. Elevated CSF levels of interleukin-2 in neuroleptic-free schizophrenic patients. Am J Psychiatry. 1993;150(9):1408-10.

7. McAllister CG, Van Kammen DP, Rehn TJ, Miller AL, Gurklis J, Kelley ME, Yao J, Peters JL. Increases in CSF levels of interleukin2 in schizophrenia: effects of recurrence of psychosis and medication status. Am J Psychiatry. 1995;152(9):1291-7.

8. Müller N, Dobmeier P, Empl M, Riedel M, Schwarz M, Ackenheil M. Soluble IL-6 receptors in the serum and cerebrospinal fluid of paraniod schizophrenic patients. Eur Psychiatry. 1997;12(6):294-9.

9. Van Kammen DP, McAllister-Sistilli CG, Kelley ME. Relationship between immune and behavioral measures in schizophrenia. In: Wieselmann G (ed) Current Update in Psychoimmunology Springer Verlag Wien: NY, 1997, pp. 51-55.

10. Müller N, Ulmschneider M, Scheppach C, Schwarz MJ, Ackenheil M, Möller HJ, et al. COX-2 inhibition as a treatment approach in schizophrenia: immunological considerations and clinical effects of celecoxib add-on therapy. Eur Arch Psychiatry Clin Neurosci. 2004;254(1):14-22.

11. Müller N, Riedel M, Schwarz MJ, Engel RR. Clinical effects of COX-2 inhibitors on cognition in schizophrenia. Eur Arch Psychiatry Clin Neurosci. 2005;255(2):149-51

12. Müller N, Strassnig M, Schwarz MJ, Ulmschneider M, Riedel M. COX-2 inhibitors as adjunctive therapy in schizophrenia. Expert Opin Investig Drugs. 2004;13(8):1033-44.

13. Hewett SJ, Uliasz TF, Vidwans AS, Hewett JA. Cyclooxygenase-2 contributes to N-methyl-D-aspartate-mediated neuronal cell death in primary cortical cell culture. J Pharmacol Exp Ther. 2000;293(2):417-25.

14. Müller N, Riedel M, Scheppach C, Brandstätter B, Sokullu S, Krampe K, Ulmschneider M, Engel RR, Möller HJ, Schwarz MJ. Beneficial antipsychotic effects of celecoxib add-on therapy compared to risperidone alone in schizophrenia. Am J Psychiatry. 2002;159(6):1029-34.

15. Müller N, Empl M, Riedel M, Schwarz M, Ackenheil M. Neuroleptic treatment increases soluble IL-2 receptors and decreases soluble IL6 receptors in schizophrenia. Eur Arch Psychiatry Clin Neurosci. 1997;247(6):308-13.
16. Lin A, Kenis G, Bignotti S, Tura GJ, De Jong R, Bosmans E, Pioli R, Altamura C, Scharpé S, Maes M. The inflammatory response system in treatment-resistant schizophrenia: increased serum interleukin-6. Schizophr Res. 1998;32(1):9-15.

17. Maes M, Bosmans E, Calabrese J, Smith R, Meltzer HY. IL-2 and IL-6 in schizophrenia and mania: effects of neuroleptics and mood stabilizers. J Psychiatr Res. 1995;29(2):141-52.

18. Yermakova A, Banion MK. Cyclooxygenases in the Central Nervous System: implication for treatment of neurogical disorders. Curr Pharm Des. 2000;6(17):1755-6.

19. Meyer U, Schwarz MJ, Müller N. Inflammatory processes in schizophrenia: a promising neuroimmunological target for the treatment of negative/cognitive symptoms and beyond. Pharmacol Ther. 2011;132(1):96-110.

20. Hochberg MC. COX-2 selective inhibitors in the treatment of arthritis: a rheumatologist perspective. Curr Top Med Chem. 2005;5(5):443-8.

21. McGeer PL. COX -2 inhibitors: rationale and therapeutic potential for Alzheimer's disease. Drug Aging. 2000;17(1):1-11.

22. Akhondzadeh S, Tabatabaee M, Amini H, Ahmadi Abhari SA, Abbasi $\mathrm{SH}$, Behnam B. Celecoxib as adjunctive therapy in schizophrenia: a double-blind, randomized and placebo-controlled trial. Schizophr Res. 2007;90(1-3):179-85.

23. Mizuno M, Sotoyama H, Narita E, Kawamura H, Namba H, Zheng Y, Eda T, Nawa H. A cyclooxygenase-2 inhibitor ameliorates behavioral impairments induced by striatal administration of epidermal growth factor. J Neurosci. 2007;27(38):10116-27.

24. Rapaport MH, Delrahim KK, Bresee CJ, Maddux RE, Ahmadpour O, Dolnak D. Celecoxib augmentation of continuously ill patients with schizophrenia. Biol Psychiatry. 2005;57(12):1594-6.

25. Stolk P, Souverein PC, Leufkens HG, Weil JG, Egberts AC, Heerdink ER. The association between exposure to COX-2 inhibitors and schizophrenia deterioration. A nested case-control study. Pharmacopsychiatry. 2007;40(3):111-5.

26. Ginovart N, Kapur S. Role of dopamine d(2) receptors for antipsychotic activity. Handb Exp Pharmacol. 2012;(212):27-52.

27. Partitt K. Martindale: the complete drug reference. 32nd ed. Massachusetts: Pharmacological Press; 1999. pp. 63-6, 657-60.

28. Røge R, Møller BK, Andersen CR, Correll CU, Nielsen J. Immunomodulatory effects of clozapine and their clinical implications: what have we learned so far?. Schizophr Res. 2012;140(1-3):204-13.

29. Meltzer HY. Update on Typical and Atypical Antipsychotic Drugs. Annu Rev Med. 2013;64:393-406.

30. Hardman IG, Limbard LE. Goodman \& Gilman's the Pharmacological Basis of Therapeutics. 10 ${ }^{\text {th }}$ ed. New York: Mc Graw - Hill; 2001. pp. 485-500, 715 .

31. Meltzer HY, Massey BW, Horiguchi M. Serotonin receptors as targets for drugs useful to treat psychosis and cognitive impairment in schizophrenia. Curr Pharm Biotechnol. 2012;13(8):1572-86.

32. Suzuki T, Remington G, Mulsant BH, et al. Treatment resistant schizophrenia and response to antipsychotics: a review. Schizophr Res. 2011;133(1-3):54-62.

33. Baik EJ, Kim EJ, Lee SH, Moon C. Cyclo-oxygenase-2 selective inhibitors aggravate kainic and induced seizure and neuronal cell death in the hippocampus. Brain Res. 1999; 843(1-2):118-29.

34. Lantz MS, Giambanco V. Acute onset of auditory hallucination after initiation of celecoxib therapy. Am J Psychiatry. 2000;157(6):10223.

35. Kay SR, Fiszbein A, Opler LA: The Positive and Negative Syndrome Scale (PANSS) for schizophrenia. Schizophr Bull 1987; 13:261-276.

36. Kay SR, Opler LA, Lindenmayer JP. Reliability and validity of the positive and negative syndrome scale for schizophrenics. Psychiatry Res. 1988;23(1):99-110.

37. Kianmanesh S, Jenaabadi $H$. The study of difference between the frequency of positive and negative symptoms of schizophrenia in people with different cultural backgrounds. Glob J Scientific Res. 2014;2(5):124-7.

38. Müller N, Riedel M, Schwarz MJ. Psychotropic effects of COX-2 inhibitors--a possible new approach for the treatment of psychiatric disorders. Pharmacopsychiatry. 2004;37(6):266-9.

39. Bresee CJ, Delrahim K, Maddux RE, Dolnak D, Ahmadpour O, Rapaport $\mathrm{MH}$. The effects of celecoxib augmentation on cytokine levels in schizophrenia. Int J Neuropsychopharmacol. 2006;9(3):343-8.

40. Bian Q, Kato T, Monji A, Hashioka S, Mizoguchi Y, Horikawa $\mathrm{H}$, Kanba S. The effect of atypical antipsychotics, perospirone, 
ziprasidone and quetiapine on microglial activation induced by interferon-gamma. Prog Neuropsychopharmacol Biol Psychiatry. 2008;32(1):42-8

41. Jann MW, Saklad SR, Ereshefsky L, Richards AL, Harrington CA, Davis CM. Effects of smoking on haloperidol and reduced haloperidol plasma concentrations and haloperidol clearance. Psychopharmacology (Ber). 1986;90(4):468-70.

42. Dysken MW, Cumming RJ, Channon RA, Davis JM. Drug interaction between ascorbic acid and fluphenazine. JAMA 1979;241(19):2008
43. Kulhanek F, Linde OK, Meisenberg G. Precipitation of antipsychotic drugs in interaction with coffee or tea. Lancet. 1979;1(8152):1130-1.

44. Bowen S, Taylor KM, Gibb IA. Effect of coffee and tea on blood levels and efficacy of antipsychotic drugs. Lancet 1981;1(8231):1217-18

45. Sommer IE, de Witte L, Begemann M, Kahn RS. Nonsteroidal antiinflammatory drugs in schizophrenia: ready for practice or a good start? A meta-analysis. J Clin Psychiatry. 2012;73(4):414-9.

46. Krebs M, Leopold K, Hinzpeter A, Schaefer M. Neuroprotective agents in schizophrenia and affective disorders. Expert Opin Pharmacother. 2006;7(7):837-48 